\title{
Intimacy as a Concept: Explaining Social Change in the Context of Globalisation or Another Form of Ethnocentricism?
}

\author{
by Lynn Jamieson \\ University of Edinburgh
}

\author{
Sociological Research Online, 16 (4) 15 \\ <http://www. socresonline.org.uk/16/4/15.htm/> \\ $10.5153 /$ sro. 2497
}

Received: 15 Jun 2011 Accepted: 3 Nov 2011 Published: 30 Nov 2011

\begin{abstract}
This article focuses on intimacy in terms of its analytical potential for understanding social change without the one-nation blinkers sometimes referred to as 'methodological nationalism' and without Euro-NorthAmerican ethnocentrism. Extending from the concept of family practices, practices of intimacy are sketched and examples considered across cultures. The cultural celebration and use of the term 'intimacy' is not universal, but practices of intimacy are present in all cultures. The relationship of intimacy to its conceptual relatives is clarified. A brief discussion of subjectivity and social integration restates the relevance of intimate relationships and practices of intimacy to understanding social change in an era of globalisation, despite the theoretical turn away from embodied face to face relationships. Illustrations concerning intimacy and social change in two areas of personal life, parental authority and gender relations, indicate that practices of intimacy can re-inscribe inequalities such as those of age, class and gender as well as subvert them and that attention to practices of intimacy can assist the need to explain continuity as well as change.
\end{abstract}

\section{Keywords: Love and Intimacy, Globalization, Ethnocentric, Social Change, Inequality, Di course, Family Practices}

\section{Introduction}

1.1 Defining Intimacy: The focus of this article is on intimacy, intimate relationships and practices of intimacy. Everyday English-language uses of the term intimacy vary with it being understood differently according to cultural and historical frames of reference. Regardless of these, however, intimacy refers to the quality of close connection between people and the process of building this quality. Although there may be no universal definition, intimate relationships are a type of personal relationships that are subjectively experienced and may also be socially recognized as close. The quality of 'closeness' that is indicated by intimacy can be emotional and cognitive, with subjective experiences including a feeling of mutual love, being 'of like mind' and special to each other. Closeness may also be physical, bodily intimacy, although an intimate relationship need not be sexual and both bodily and sexual contact can occur without intimacy. This is a broader definition than one which limits intimacy to deep 'knowing' of the other person; rather than placing particular emphasis on knowing (Morgan 2009), knowing is just one of a number of practices that may create intimacy.

1.2 The term, 'practices of intimacy', builds on the concept of 'family practices' developed by the sociologist David Morgan (1996, 2011, see also his contribution to this Special Section). The concept of 'family practices' was developed to avoid preconceived definitions of 'family' and instead focus on the culturally and historically variable practices people use to 'do' family, to create an experience of particular places, relationships and events as meaning and expressing family. 'Practices of intimacy' refer to practices which enable, generate and sustain a subjective sense of closeness and being attuned and special to each other. Practices of intimacy and family practices overlap in cultures which valorise families and intimacy and take it for granted that intimacy is an aspect of family life.

1.3 Intimacy as a concept complements rather than supplants terms which seek to categorise types of personal relationships such as family, friends and kin and overlaps with other concepts seeking to capture the quality of relationships and the processes that bind people together, like love. In everyday English 
language use in Euro-North American cultures, the phrase 'nearest and dearest' often alternates with 'friends and family' to signal key intimate and personal relationships. However, how useful are the concepts of intimacy and practices of intimacy outside of these cultures? Even if idealising particular forms of intimacy is culturally and historically specific, is there, nevertheless, analytical value in giving consideration to practices of intimacy across cultures?

1.4 Intimacy and the 'Western' Individual?: To what extent is this conceptualisation of intimacy dependent on a construction of the individual which is a peculiarly 'Western' form of personhood and subjectivity? 'Western' cultures have a long history of conceptualising persons as autonomous individuals who are proprietors of their own person (Macpherson 1962). In the case of England, Macfarlane argued this goes back to at least the $13^{\text {th }}$ century (Macfarlane, 1978) although other scholars stress watershed in later centuries. Sociological traditions within Euro-North American social science have generally taken the view that a cultural emphasis on the sanctity of the individual co-exists with the social fact of interdependence between individuals. The theoretical traditions of symbolic interactionism and phenomenology, for example, suggest that people are everywhere and always embedded in, reliant on and constructed by social relationships. Feminists' scholarship has argued that conceptualizations of the individual passed off the history of being proprietor of his own person as if gender neutral and denying the class and gender systems that made this sense of self-possession possible (Pateman 1988). From such perspectives, there is an element of mythology about 'Western individualism' since all individuals rely on and are shaped by others to some degree. Nevertheless, some types of intimate relationships may require culturally specific beliefs in the autonomy of the self and a sense of freedom to manoeuvre before they can flourish (Carrier 1999).

1.5 Particular claims about a link between intimacy and cultural emphasis on self-making, that is freedom to be and make one's self, appeared in academic discussions of social change in Euro-North American personal life at the end of the twentieth century. Using rather different arguments, Giddens (1992), Bauman (1995), Beck with Beck-Gernsheim (1995) and Castells (1997), pointed to a heightened sense of individual identity expressed by practice of self-centred, self-reflective autobiographical narration emerging from the social and economic conditions of global capitalism. Of these, Giddens's, (1992) is perhaps the most quoted account that explicitly links intimacy and the self; in his view, intimacy is built through a dialogue of mutual self disclosure between equals, revealing inner qualities and feelings, simultaneously generating a self-reinforcing narration of the self. This set of authors subsequently captured the imagination of many scholars, despite also attracting much criticism. Critiques of Giddens included reviews of Euro-North American research showing that disclosing intimacy is not the only item in the repertoire of practices of intimacy and that gender inequalities can persist alongside intimacy (Jamieson, 1998, 1999). Some of the subsequent critics suggest over generalisation, even with respect to the fate of intimacy and personal life in the richest and highest-consumption societies of the globe; others contest what they read as the suggestion that 'the West' was leading where others are likely to follow.

1.6 The emphasis on individualisation as driver of change in personal life has been comprehensively and persistently challenged (e.g. Brannen and Neilson 2005, Bjornberg and Kollind 2005, Charles et al, 2008, Crow 2002, Duncan and Smith 2006, Irwin 2005, Jamieson 1998 1999, Smart and Shipman 2004, Smart 2007). Critics of the treatment of individualism noted the neglect of evidence showing the coexistence of intimacy and the valuing of interdependence of kin, genders and generations and forms of collectivism (Smart and Shipman 2004, Magazine and Sanchez 2007, Thornton 2001, 2005, Quah 2007). Research on Asian cultures experiencing significant economic development and growth in consumerism often found young people steering a middle way, both adopting practices associated with individualism - couples setting up their own homes rather than living in three-generational families, choosing marriage partners rather than arranged marriages - and continuing to take collective responsibility for their elders and ancestors (Croll 2006, Hansen \& Pang 2010, Ikels 2004, Janelli \& Yim 2004, Quah 2008, Yan 2000).

1.7 Intimacy and Globalisation: Addressing broader and more general social concerns, by the end of the twentieth century, discussion of social change was focussed on processes with a global reach increasingly referred to by the shorthand term globalisation. This included the restructuring of capitalist markets in tandem with socio-technical systems of rapid transport, digitised mass media, mass migrations and global social movements. While the structural, economic and political circumstances identified with globalisation are not historically unique (Stanley et al 2010), the use of the term 'globalisation' became part of global mass media talk about social change. Global media circulate stereotypical ideals of intimacy celebrating relationships of individual equals impacting on imaginations across locally-specific social worlds (Appaduri, 1996). Global stereotypes do not necessarily erase other idealized notions of intimacy or level diversity in practices in lives as lived. Anthropologists are mapping the dialectic between new expectations about the quality of personal relationships, fuelled by mass media images of intimacy, and conventional arrangements, as people seek to exercise claims to 'modernity' or more traditional values (Cole and Thomas 2010, Hirsch and Wardlow 2006, Padilla et al 2007, Rebhun 1999, Mody 2008).

1.8 In social science the conduct of personal life has been seen as implicated in driving structural, economic and political changes refered to by the shorthand of globalisation or as an outcome of such changes envisoned as primarilyhappening elsewhere. Castells' (1997) view of the global demise of men's authority over women in familial and domestic life deployed both perspectives. On the one hand, he suggested that global markets in goods and ideas promote forms of individualism that are corrosive of patriarchy and all traditional authority. On the other hand, he acknowledged women seeking to change their familial and domestic life as an aspect of feminist movements effecting social change. Giddens (1992) unequivocally suggested personal life effects social change by spreading democracy through the search for more intimate and equal relationships. Bauman (1995) and Beck and Beck- Gernsheim (1995), in their early writing, depicted personal life as the victim of the advancing frontiers of capitalist market fuelling selfobsessed individualism and consumption to detriment of the skills and capacities to sustain intimacy. 
1.9 The discussion which follows draws on a range of research and does not support visions of a unidirectional relationship between intimate personal life and social change. Intimate relationships are implicated in innovative individual efforts to change biographies and histories but they are also implicated in protective responses to enforced change and in the re-creation of tradition. I believe this variation reaffirms rather than undermines the theoretical relevance of intimate relationships to fuller understanding of the changes bundled up in the term globalisation. The next two sections do more specific theoretical work, elaborating what is meant by practices of intimacy and then clarifying how intimacy stands alongside other frequently used concepts in discussions of personal life, before returning to the bigger issue of social change. The final sections of the article return to the changes parcelled up as globalisation through discussion of how intimacy is implicated in processes of social integration and social reproduction.

\section{Practices of Intimacy}

2.1 Practices of intimacy refer to practices which cumulatively and in combination enable, create and sustain a sense of a close and special quality of a relationship between people. In psychology, efforts have been made to operationalise 'closeness' in interpersonal relationships by measuring interdependence or mutual influence (Berscheid et al 2008). In a sociological investigation, a repertoire of practices of intimacy has to be derived from research documenting how people conduct themselves within families, parent-child relationships, couples, sexual relationships and friendships or any other relationship that is experienced as and socially recognised as having a special quality of close connection.

2.2 In a review of the relevant Euro-North American research literature I indicate that even in the parts of the worlds and period of which Giddens wrote (1992), intimacy is not solely or perhaps even primarily practiced through self disclosure (Jamieson, 1998, 1999) but that it relates to a wider repertoire of practices. The component practices - giving to, sharing with, spending time with, knowing, practically caring for, feeling attachment to, expressing affection for - are not exclusively about intimacy. That is, each practice tends to produce intimacy but is not a sufficient condition. For example, the close association of sharing a prison cell involves both spending time with and access to privileged knowledge about a cell mate but development of any shared sense of being close might be carefully resisted.

2.3 The deployment of such practices as spending time and knowing may be recognised as qualitatively different when 'doing intimacy'. For example, in a Euro-North American context intimacy built through spending time together involves a sense of electing to do so and having taken for granted privilege in access to each other's time perhaps including certain types of time: e.g. 'undivided', 'quality' and 'on demand'. Similarly, access to knowledge goes beyond mutual offering of information to taken for granted privileged access to news, being trusted with back-stage and secret information and a relationship-specific sense of uniquely knowing each other. This knowing, however, need not rely on talk but can also draw on non-verbal memories of a common history to assume shared knowledge and understandings.

2.4 The performing or receiving of practical acts of care as a practice of intimacy is often underplayed in academic and popular discussions which, like Giddens, place a dialogue of mutual self-exposure at the heart of intimacy. However, research on couple, parent-child and friendship relationships suggests the continued potency of the adage 'actions speak louder than words' (Jamieson 1998, Gabb 2008). A sense that an intimate has failed to deliver practical care when it is exceptionally needed, or that routine practical care is not forthcoming when the social and cultural context suggests that it should be, devalues and undermines other practices of intimacy.

2.5 Morgan (2011) notes that 'practice' can encompass both innovative behaviour and habitual or institutionalised actions consistent with pre-existing scripts. With respect to family practices, individuals typically come into a set of practices that are already partially shaped by 'legal prescriptions, economic constraints and cultural conditions' (Morgan, 2011: 7). It could therefore be expected that many family practices will be processes sustaining the conventional arrangements for partnering and parenting that receive legal, economic and cultural support. Just as family practices might fit with and reproduce conventional scripts, so too might practices of intimacy. Indeed, much has been written about the extent of cultural scripting in how people conduct themselves in developing romantic and sexual relationships (Banaji 2006, Duncombe, and Marsden1995, Gagnon and Simon 1973, Uberoi 2006). The possibilities of developing intimacy are also modified by institutionalised arrangements recognising and protecting particular types of personal relationships as legitimate partners, parents and kin. For example, diversity in how people live out their personal lives in Europe and North America has not erased institutional arrangements privileging married heterosexual couples and two-parent family parenting relationships and ideal-typical images of intimacy are often depicted in these family forms.

2.6 The fact that intimacy is built by practices which are not exclusive about doing intimacy explains the fuzziness of the concept and its potential overlap with related constellations of feelings and predispositions sharing some of the component practices such as trust, empathy and respect. Accounts of how and why particular combinations of elements are sufficient to sustain intimacy have to be derived from detailed studies of actual relationships.

2.7 Existing research suggests that elements of practices of intimacy can be transposable, that is, one practice of intimacy is sometimes able to stand in for others, making it as -if other practices of intimacy were also in place. Studies of heterosexual couples in Europe and North-America, for example, have shown that expressing love and care for someone can compensate for inequality in the giving and receiving practical care even among couples who believe in and formerly practiced greater equality. This is demonstrated by couples bringing up young children believing mothers and fathers should be equally involved in their parenting but, nevertheless, reverting to conventional gendered specialisation in caring and providing following the birth of a child. The consequent asymmetries and inequalities are accepted as a temporary phase and men's expressions of love and occasional contributions carry particular weight for 
women doing most of the practical caring (eg. Backett 1982, Harris 2006, Hertz 1986). Without compensatory gestures, a sense of inequality can reach a tipping point. The unequal division of labour is then seen as exemplifying an absence of acts of care, devaluing other practices of intimacy, now seen as tokenistic. This makes sense of how it is possible to take a relationship for granted as a 'good relationship' despite deficits in the repertoire of practices of intimacy.

2.8 This breaking down of the process of creating intimate relationships into practices might enable us to see why some contexts support some kinds of practices more than others and help us to think through what the consequences might be for individuals and the wider social fabric when such support is modified. It leaves open the possibility of integrating discussion of practices of intimacy into more general social theories of selves, identity and social worlds explaining social reproduction and social integration, such as the construction of 'community' or 'social capital' as well as social division and social exclusion.

\section{Intimacy's Conceptual Relatives}

3.1 I now want to further elaborate the idea that as an analytic category 'intimate relationships' will be more or less distinct from or overlapping with family, kin and relatives or relations in different cultures and periods. Family, kin and relatives are often formally defined in terms of traditional or legal rules recognising and protecting particular partnership, parenting, household and inheritance arrangements. In practice, a subjective sense of intimacy may map more or less onto 'being related' or 'relatedness' (Carsten 2000, 2004) and living 'connected lives' (Smart 2007). Subjective experience rarely maps precisely to formal' rules. Intimate relationships might include friends and lovers excluded from family or kin, except by redefinitions that bend the conventions. Some family or kin may never be experienced as intimates. An expectation of love and intimacy is part of the current normative understanding of 'friends and family' of Euro-North American cultures.

3.2 Anthropologists have documented experience reported as love and intimacy on every continent (Cole and Thomas 2009, Jankowiak 2008, Hirsch and Wardlow 2006, Li 2008, Mody 2008, Rebhun 1999). The near universality of romantic passionate love relationships between couples has been asserted in a recent text (Jankowiak and Paladiono, 2008). The universality of friendship as a form of intimacy is more contested. In the context of British society, some academic commentators suggest that friendship relationships are replacing couple relationships as the key intimate relationship of adulthood (e.g. Roseneil and Budgeon 2004, Weeks 2007 see also discussion in Spencer and Pahl, 2006 and Jamieson et al 2006). It has also been suggested that friendship is the purest form of intimacy, albeit perhaps by taking what may be a Western view of friendship, a freely chosen relationship between equals sustained only by mutual pleasure in quality of the relationship (Silver 1997, Carrier 1999). Bell and Coleman (1999) note that cultural variation in notions of autonomy, privacy and the appropriateness of affect make it unlikely that 'the Western middle-class idea of friendship as involving a personal, spontaneous, private relationship between particular individuals' is universal (Bell and Coleman 1999: 3). At the same time, examples from Europe, China, East Africa and Brazil make it clear that friendship involving affect and intimacy, or 'some form of sentiment or at least empathy and common ground between persons' (1999: 16) is found across the globe.

3.3 Conceptually, 'love' and 'intimacy' are close relatives. Everyday uses and academic classifications of love are numerous and include interchanging the terms love and intimacy. However, love is more often conceptualised as an emotion (Evans 2003), embodied affect, and, in this usage, love becomes an attribute of a person rather than a quality of connection between people. Feelings of love can occur despite lack of reciprocity and, even, in the absence of any relationship with the person who is loved. Intimacy always refers to some form of interpersonal connections but typically flags up a pattern of interactions that is durable overtime and acknowledged by both parties as a relationship. Expressing feelings of love is a practice of intimacy; exchanging declarations of love can build intimacy. However, in many context of developing couple relationship, declarations of love need to operate in concert with other practices of intimacy for expressed feelings to be heard as authentic rather than suspect.

3.4 The significance of love to intimacy is illustrated by instances of their separation. Relationships between clients and professional carers or service providers can involve practices of intimacy such as self-disclosure (counsellor-client relationships), physical contact and practical care (paid carers-client relationships) and sexual contact (sex worker-client relationships) without love. Codes of practice mark such relationships as professional or commercial rather than personal but the absence of love, an aspect of this distinction, is often subverted, obfuscated or experienced as problematic. This is exemplified when those who rely on professional care report that the professionals they most value are those who behave like friends or family. This is true, for example, for vulnerable children and young people speaking about their various support workers and cares in the UK (Clayden and Stein 2008, Philip 2008). It is also exemplified by the literature on sex workers and their clients which documents claims of and demands for the performances of emotional, love like services, as well as sexual services, in order to deliberately blur the boundaries between intimate relationships and commercial transaction (Bernstein 2007, Ding and Ho 2008, Sanders 2008).

3.5 Anthropologists have used similarities in practices of intimacy across cultures to critique assumptions linking particular forms of love and intimacy to 'Western' social conditions and/or so-called 'Western' conception of the self. Cole and Thomas (2009), for example, attribute the neglect of the study of love in Africa to an ethnocentric assumption that love is a 'Western' practice. Even when ethnographies document differences in practices of love and intimacy across cultures, they often also observe fundamental similarities. For example, in discussing the Lahu people of Southwest China, Du stresses that the cultural celebration of intimacy between couples is distinctly non-Western- 'intimacy is manifested primarily in the harmonious function of a couple in their shared familial and social responsibilities, rather than in private emotional attachment between husband and wife' (Du, 2008, 101). However, Du also makes it clear that the 'harmonious function', integral to survival given livelihood is based on the hard physical work of 
subsistence, is not only a matter of public display but a subjectively experienced emotional and mental harmony that couples enjoy in private. Indeed, Du's account supports the view of a shared repertoire of practices of intimacy among couples across a wide range of circumstances including cultural contexts that are hostile to celebrating autonomous individualism.

3.6 Intimacy has also been documented in marriage arrangements in which partners are chosen by parents or other kin rather than couples themselves. For example, the ethnography of Röttger-Rössler (2008) documents how the Makassar people of Indonesian created cultural pathways to love and intimacy for young men and women who led gender segregated lives until an arranged marriage involving little prior knowledge of their bride/groom. This process started with procedures for finding suitably matched couples prior to the marriage and moved through a series of rituals traditionally staggered over months. These were intended as triggers of appropriate feelings and of previously prohibited practices of intimacy. One key, ritual, traditionally performed ten days after the marriage, translated as 'making into speaking partners'. Another traditionally occurred 40 days later, involved placing of the couple in bed together and 'making mutually good or well disposed'. These traditions have been much eroded and were always shadowed by instances of elopements and 'self-made' marriages initiated by the couple. Röttger-Rössler compared accounts of intimacy in both arranged and 'self made' marriages, finding instances in which couples report the experience of being 'always in each other's thoughts', in both types of marriage. A Makassar classification ranked different degrees of intimacy culminating in this, the most intense, and a form of intimacy that can also be found in Western accounts of couple relationships. Although practices of intimacy were kick-started by rituals rather than developing with the grain of mutual attraction or pleasure in each other's company, the biography of some arranged-marriage Makassar couples culminated in an intimacy that was as intense as any love marriages in a Western culture.

\section{Intimacy, Subjectivity and Social Integration}

4.1 Close personal relationships were given central place in early twentieth century sociological accounts of the social construction of selves and social worlds and the articulation between the two. In accounts deriving from the theoretical traditions of symbolic interactionism (Mead 1927), phenomenology (Shutz 1932), Parsonian functionalism (Parsons and Bales 1956) or drawing on psychoanalytic traditions, emotionally close and physically proximate intimates shape selves in childhood and anchor adult individuals in their social worlds. Over the decades, the insights of these traditions have been drawn on and reworked. In his account of the dialectic between individual agency and social structure, Giddens (1984) restated the importance of intimates, particularly parent-child relationships, for fostering a subjective orientation of confidence, in continuity of the self and order in the world, necessary for individuals to collectively sustain social order. His later work (1991) re-emphasised the importance of this sense of ontological security which protects the individual from constant anxiety and a sense of chaos, a generalised trust first established in early childhood through intimate relationships. The theorising of Pierre Bourdieu (1998) also shows a debt to such traditions, although his critics might argue without sufficient development (e.g. Crossley 2007, McNay 2008). Nevertheless, emotionally close and proximate others typically play major parts in shaping 'habitus', the 'structuring structures' of an individual's predispositions creating his or her unease or comfort in different social settings, a key concept in Bourdieu's theory of social inclusion and exclusion and of how inequalities are reproduced.

4.2 In contrast, some more recent theoretical writing minimises the role of intimates in the construction of selves and social worlds. A major point of such departure emerges from the philosophy of Michel Foucault. Although familial relationships are acknowledged in his account of the shaping of selves and the social production of self-disciplined bodies (Foucault 1978), it is his analysis of power, knowledge and discourse in Western cultures that has inspired social scientists. Critics have argued that this is a teleological account of social change, as it uses the purposes served by discourse as an explanation rather than providing a history that identifies causes (Wickham and Kendal 2007). Nevertheless, Foucault's account, as elaborated by Rose and others, persuasively proclaimed individual selves to be more profoundly shaped by discourse than by personal relationships. In this account, the notion of the self as 'individuals inhabited by an inner psychology that animates and explains our conduct and strives for self-realization, selfesteem, and self-fulfilment in everyday life' (Rose, 1996: 3) is linked to the emergence of psychology, psychiatry, psychotherapy and psychoanalysis and the deployment of their expertise by democratic states. This understanding of the self can also be described as a regulatory regime, a way of thinking that frames, shapes and creates our practices of the self. However, arguably this does not erase the relevance of intimates; if Western conceptions of the self are a diffuse and pervasive regulatory regime, significant processes and phases of self-regulation are negotiated in interpersonal exchanges between friends and family.

4.3 Part of the attraction of a Foucauldian approach is that a shift in emphasis towards mediated and imagined relationships and disembodied discourse seems very apposite in an age of digital interconnectivity and global media. There are other routes to this emphasis on the power of media and imagined relationships in shaping subjectivities. Drawing on the explanatory value of Anderson's conceptualization of the integrating power of nationalism as 'imagined community'(1991), Calhoun argues that imaginary solidarities with unknown others both provide social integration and shape personal identities (e.g. Calhoun 1991, 1992, 2008).

4.4 By the end of the twentieth century many authors were adopting the metaphor of network and flows that were dominant in the work of Castells (1997). Locating selves in social worlds through this conceptualization of network blurs the significance of the distinction between being connected to embodied know proximate others and connections to unseen and unknown others. Wellman and colleagues (2006) suggest 'networked individualism' signalled a shift from long-term loyalties to family, friends and placebased communities to more fluid and dispersed social networks. Some commentators focus more narrowly on the dominant messages of the mass media. Illouz, for example, like Bauman, suggested that an 
emphasis on intimacy in the context of a voracious consumer culture leaves relationships: 'dispassionate, rationalised, and susceptible to crass utilitarianism' (Illouz 2007: 109, see also Bauman 2003).

4.5 Theorists who place heavy theoretical weight on the power of discourse, are often disinclined to trawl the research evidence detailing the everyday interactions of personal intimate lives for confirmation or counter examples. Studies that start with intimate lives often acknowledged the influence of popular discourses about intimacy. Mass media representations of intimacy such as that various versions of romance carried by Hollwood, Bollywood and the like, transcend national boundaries. Such discourses enter imaginations as people 'stage their own romance' (Banaji 2006, Duncombe and Marsden 1995, Uberoi 2006) but as scripts that people draw on, modify and sometimes subvert. Neither acknowledgement of the importance of imagined relationships nor of the power of discourse to prompt the imagining of relationships need erase the significance of intimacy with embodied living others.

4.6 It is unhelpful and unnecessary to deny the significance of intimate relationships in order to acknowledge the impact on subjectivities and identities of many forms of discourse, such as the oft repeated stereotypes and scripts of popular culture and the pervasive popularisations of expert knowledge delivered through mass media. Children are not brought up solely or primarily by discourse and, across cultures, the ability to function as an adult is profoundly shaped by the quality of intimate relationships in childhood. Moreover, since the pioneering work of Morley (1986) on the interaction of British family households with television, the significance of co-present personal relationships for how people hear and interpret mediated discourse has been widely acknowledged.

4.7 Study of the interaction between mass media messages and personal relationships makes more sense than treating discourse as a discrete source of causal influence. Many authors combine insights from symbolic interactionism or phenomenology with attention to the power of discourse. The social psychologist Hewitt (2007) and the feminist sociologist Smith (1987) provide contrasting examples. Extending Mead's concept of 'generalised other', internal conversation with mediated messages of discourse may become incorporated into a sense of self but this means that the internal conversation is in interaction with the internalized legacy of conversations with embodied and loved others (Holdsworth and Morgan, 2009). There is an iterative two way interaction. In media saturated contexts, a legacy of mass media communicated discourse may always be present in the here and now of personal interaction. This includes a presence in how intimates see themselves and act as friends, lovers, mother, fathers and so on.

4.8 Fully exploring the consequentiality of intimate relationships for selves and social worlds requires articulation with a theory of the development of (gendered, sexual, embodied) self/identities. This in turn must include explicating ontological security by taking a position on what all humans require by way of social recognition and 'good enough' parenting. However, such a theory cannot be ethnocentric and any national starting point must acknowledge interaction between processes shaping selfhood and an array of social systems (e.g. cultural, economic, political, technical, 'natural') or 'fields' with geographical spans from local to global.

\section{Practices of Intimacy and Parental Authority}

5.1 A shift over time from traditional disciplinary authority of parents over children to more intimate and indulgent relationships between parents and children has been claimed in Western and Asian contexts. Contemporary discussion of parent-child relationships in Asia foregrounds concerns about processes of globalisation and Western values undermining filial piety, along with the collective values of loyalty to the family and respect for elders (Croll 2006, Hansen \& Pang 2010, Ikels 2004, Janelli \& Yim 2004, Quah 2008, Yan 2010). In China, the one child policy is often seen as exacerbating a shift in power from young to old (Fong 2004).

5.2 The picture built by empirical research is much more nuanced. In a review of research across Asia, acknowledging that a finer grain analysis might show considerable variation, Croll (2006) is confident that the emergent picture is of reaffirmation of collective values in the form of an intergenerational contract of reciprocal care between parents and children. Moreover, it is no accidental that such an intergenerational contract persists despite a shift towards much greater indulgence of children: 'intensification of spending on children is rationalized not only as an expression of affection and a sign of devotion, but also as the strategic nurturing of long-term gratitude or support and indebtedness to parents' (Croll, 2006: 479). In other words, over time parents have replaced appeals to traditional authority with practices of intimacy, although the cultural depictions of close relationships emphasise devotion rather than the type of self-disclosing intimacy celebrated in the West. Nevertheless, Croll suggests that parents' practices of intimacy have been heightened by more or less conscious calculations concerning how to ensure their children will care for them in their old age.

5.3 A shift toward more intimate parenting does not necessarily mean a relinquishing of parental authority. There are many more ways in which parents can seek control over their children than appeals to tradition. In an attempt to do their best for their children, and through them, bring advantage to their family, parents sometimes make radical changes to children's lives. For example, Huang and Yeoh (2005) describe Chinese mothers who migrate with their child to Singapore to maximize his or her educational prospects. This dislocation involves considerable sacrifice. The mother is removed from her partnership relationship, employment prospects and loses much of her selfhood in this radical prioritising of her child's education. The child is subjected to an alien, friendless and often hostile school environment, with only his or her mother's love for support. This is a high risk collective project unilaterally orchestrated by parents; and practices of intimacy are implicated in seeking its success.

5.4 In a Western context, Giddens's view $(1991,1992)$ that parents and children become as-if equals as 
parents sought friendship with their children has been contested as under-estimating the persistence of age inequalities and parental power (Jamieson 1998, 1999). Western studies have also shown that the talk that parents view as primarily a practice of intimacy, as well as 'keeping tabs' on their children, is regarded by their children as primarily a practice of surveillance which threatens the exercise control (Kurz 2006, Solomon et al 2002).

5.5 The Western research literature on parent-child relationships also documents significant variation in practices of intimacy by social class and ethnicity. Different styles of using praise and discipline have been attributed to class-specific experience of occupying subordinate or superordinate positions; taking it for granted that children must learn that they cannot always get what they want is more consistent with working-class life experience while an automatic emphasis on negotiation eschewing the use of ultimatums is more consistent with middle-class and ruling-class experience (Walkerdine and Lucey 1989). Walkerdine and Lucey described middle-class British mothers' negotiations with very young children as a control tactic which is a pretend democracy. Extending this analysis, it can be argued that the talking involved in negotiation may both encourage and complicate the practices of intimacy of self-disclosure and expression of feelings.

5.6 Practices of intimacy might then overlap with and become enmeshed in the reproduction of generational power. Similarly, practices of intimacy can become implicated in the reproduction of class inequalities. Lareau in the US and Gillies in the UK showed how relatively privileged parents used their praise to communicate a sense of privilege to their children and in contrast, relatively disadvantaged parents communicated the value of being helpful and 'fitting in' because 'standing out' means getting in trouble or victimisation (Lareau 2003, Gillies 2005, 2007). Practices of intimacy can be implicated in the reproduction of inequalities as well as in their subversion.

\section{Intimacy and Gender Inequality}

6.1 The anthropological literature suggests that intimacy, and particularly the practice of intimacy stressed by Giddens (1991), a dialogue of self-disclosure, is increasing sought across cultures; it is less clear that this is having the effect of putting men and women on an equal footing that Giddens and Castells predicted. Surveying the anthropological literature, Padilla describes the trend to intimacy 'A growing literature has emerged in recent years that collectively depicts a global - if uneven - trend away from "traditional" notions of family that emphasize the role of social obligation in the reproduction of kinship systems and towards globalizing models of family that are increasingly based on a "love" that is chosen, deeply felt, "authentic," and profoundly personal' (Padilla et al. 2007: xv). This echoes a claimed shift in emphasis 'from institution to relationship' that has been used as a description of change in Western family life since it was suggested with respect to marriage in the US in the 1940s (Burgess and Locke 1945). Striving for intimacy is staking a claim to being modern and part of social change, seeking to 'annex the global into their practices of the modern (Appaduri, 1996: 4).

6.2 Local and national variations in conventional gender differences in conduct of family and personal life and the degree of institutionalised support for men's authority over women persist and are reinstitutionalised as well as subverted through practices of intimacy. For example, among young people brought up in Pakistani families living in Britain, the closer supervision of young women than young men persists alongside equality in parental support for education; a desire for intimacy and love in a partnership co-exists with and is dovetailed to arranged marriages involving the help of extended kin in Pakistan, (Shaw 2000). While there are also instances of love marriages, sometimes conducted in defiance of parental wishes, young British Pakistani men and women often speak of being pleased to have parental support in finding a suitable partner for a loving life-long relationship.

6.3 Shaw and Charsley (2006) demonstrate how emotional need including the desire to foster and maintain a sense of close connection between parents and children, between siblings and between the couple are balanced along with strategic kinship considerations in the construction of marriage matches. There are also consequential innovations in the use of arranged marriages by Pakistani families in Britain, particularly the practice of bringing husbands from Pakistan (Charsley 2005), which subverts the convention of the bride moving to her husband's parents' family house and puts men in the position of a 'trailing spouse', reducing men's capacity to exercise control over their wife.

6.4 Practices of intimacy are not, in themselves, automatically democratising or dismantling of patriarchal arrangements. It has been argued that equality in couple relationships is more readily achieved in same sex relationships when practices of intimacy are not channeled by pre-established patterns laid down by gendered scripts that entangle heterosexuality with men's patriarchal privileges (Weeks et al 2001, Weeks 2007 see also Rosenfeld 2007). The 1970s English language feminist adage 'it starts when you sink into his arms and ends with your arms in his sink', warned that heterosexual love masks patriarchal structures. The evidence on domestic divisions of labour in dual earner heterosexual-couple Western households suggests it retains a grain of truth. A significant body of research shows that women continue to do more of the work despite widespread acceptance of the idea of gender equality.

6.5 Research documents the complexity of the relationship between practices of intimacy and the reproduction of male privilege. For example, Hirsch $(2003,2006)$ describes marked generational changes in marital ideals in Mexico which involve a new emphasis on confianza, intimacy and mutually pleasurable sex. At the same time a husband can expect his wife to ask his permission to leave the house or to run to him with a glass of water when he whistles.

6.6 Practices sustaining intimacy with children can also re-inscribe traditional gender scripts, even in situations of radical departure from gender conventions. Writing about migrant mothers and fathers from the Philipines and their relationship to children left behind, Parreñas notes that when a father is absent, an 
arrangement regarded as more conventional than mother absence, his acts of financially providing are enough for children to assume his love. In the case of a mother's absence while earning money for the household, children have to hear how much they are missed, their mother's externalised grief, to feel secure in her love. This love can always be doubted unless it is repeatedly verbally documented in socially recognised suffering. This is despite the other practices of intimacy mothers orchestrate from a distance enquiring phone calls, co-ordinating care, putting money in jointly operated bank accounts for children and sending gifts. Moreover, fathers who are left behind and provide only minimal care, requiring the oldest daughter and other female kin to do the main burden of the housework, do not have their love called into question. Conventions about appropriate behavior for men and women mean that providing is a practice of intimacy that stands in for others for men but not women; migrant mothers must direct multiple practice of intimacy towards their children from a distance.

6.7 The research literature suggests that a sense of some participation in the 'modernity' of intimacy might make palatable relationships that could otherwise be described as inadequate or even failed. The research evidence offers many examples, from commercialized couple relationships as well as more typically personal couple relationships, of women foregrounding intimacy rather than ways in which their heterosexual relationships recreates traditional gender politics. The complaints about being called sex workers by women working as Xiajies in China, 'What I do is not just sex (xing)' (Yo and Ying 2008) reflect the fact that intimate relationships are 'modern' and worthy of being celebrated rather than stigmatized like prostitution. Ethnographies also document circumstances in which modernity involves expecting but being forced to live without the intimacy of a heterosexual life partner but finding solace in other 'modern' forms of intimacy. Shen describes Taiwanese women with husbands who take 'second wives' while working away from home for long periods on mainland China seeking solace in an online forum where posts include 'start a new life by loving oneself... we have already lost our husbands' love, we cannot give up on ourselves' (Shen, 2008: 227). Some interviewees also spoke of more traditional ways of refocusing intimacy on their children and/or their religion, than making and receiving advice to 'love themselves'. The women's reclamations of dignity were complex accommodations of claiming tradition and 'modernity' through reorientation of their practices of intimacy.

\section{Final Comments}

7.1 Intimacy refers to the quality of close connection between people and the process of building this quality Across national contexts, an increasing number of authors are drawing on the concept of intimacy, sometimes suggesting it is a force in the package of social changes referred to as globalisation. I have attempted to bring together definitional work and empirical research to clarify the concept's analytical potential. This involved directly addressing whether the concept suffers from Euro-North-American ethnocentrism and can be used without one-nation blinkers sometimes referred to as 'methodological nationalism'. The definitional work involved sketching out practices of intimacy and clarifying the relationship of intimacy to its conceptual relatives. While the term, practices of intimacy, is not used in the literature reviewed, I hope to have demonstrated its value in analysis of personal relationships and social change across continents and national contexts.

7.2 Love is intimacy's closest conceptual relative and relationships that are mutually recognised and subjectively experienced by those who love each other as relationships of love, by the definitions described here, typically involve practices of intimacy. Because a particular form of intimacy is celebrated in European and North American cultures, featuring self disclosure and expression of emotion, some analysts may resist calling forms of love relationships that are emotionally constrained and taciturn 'intimate', even when they involve a repertoire of other practices of intimacy. However, it is important not to be blinkered by a culturally and historically specific understanding of intimacy.

7.3 I have suggested that intimacy is built by practices which are present in many interpersonal interactions and found across historical and cultural contexts including those in which intimacy is not celebrated. For example, a parent actively caring for a dependent child is typically giving to, sharing with, spending time with, practically caring for, and feeling attachment to the child, all of which are practices that develop the intimacy of the relationship. This is so, even where public rhetoric inhibits the expression of affection and some forms of knowing each other, which are practices of intimacy now much celebrated, particularly in some 'Western' contexts.

7.4 I accept that intimate relationships are universally fundamental to the biographical development of ontological security, the subjectivity and sense of self necessary for history-making and social life. At the same time, I note an iterative two way interaction between intimates and 'discourse' globally circulated by mass media. This combination frames the relevance of intimate relationships to understanding social change in an era labeled by 'globalisation'. Brief discussion of intimacy and parental authority, and intimacy and gender inequality indicated that practices of intimacy can re-inscribe inequalities such as those of age, class and gender as well as subvert them. Hence, attention to practices of intimacy can assist the need to explain continuity as well as social change.

7.5 As late as 2011 Beck-Gernshheim suggested that much current European and North American writing about families and personal life remained intellectually impoverished because it was stuck within a nationstate perspective, a conceptual entrapment some commentators refer to as methodological nationalism (Wimmer and Schiller 2002, Levitt and Schiller 2004). She drew on Hochschild's (2003a and 2003b) analysis of global care chains and shifting commodity frontiers as a noteable exception. Hochschild demonstrated the exploitative interdependence of middle-class mothers in the USA on services provided by migrant workers leaving behind families in the global south. Beck-Gernshheim's critique rather underplays the significant and growing bodies of research across the social sciences discussing families and personal life beyond national borders, encompassing international, transnational, distance and mediated personal relationships. Within sociology it was already widely accepted that society should not 
be glibly equated with the boundaries of a nation state, given the global scale of many systems and the extensiveness of ties across national borders (Urry 2000), even if work in progress may not always live up to this orthodoxy.

7.6 It can also be argued that analysis conducted within the confines of one particular locality is not automatically blinkered by 'methodological nationalism'. Many studies of personal life from one local context acknowledge framing by global and transnational systems: a local economy shaped, in turn, by a global economy, and a local welfare regime bearing the stamp of supra-governmental entities such as the EU or the UN (Oinonen 2008). Irwin (2005) advocates systematic exploration of the intersection of economies, welfare regimes, gender and life course related patterns of interdependence and mutuality. Silva (2010) has studied home use as a space for intimacy and consumption; while it is a UK-base empirical study and UK homes do not represent all homes, neither her theoretical tools nor the technological transformations, socio-technical and consumption systems that are her focus are confined to the scale of the nation state.

7.7 Looking comparatively across cultures and transcending national contexts does not automatically deepen analysis or end ethnocentrism. There is a colonial history to collecting material from around the globe. The material used here is mindful of Connell's call to respect analysis from the global south (Connell 2007) and Mohanty's to acknowledge difference as well as similarity: 'in knowing difference and particularities, we can better see the connections and commonalities .... specifying difference allows us to theorize universal concerns more fully' (Mohanty, 2003: 203). There is a global interest in understanding in the ways people create and sustain a sense of 'togetherness' and significant personal 'relationships' in everyday life. Key questions - about equalities or inequalities, justice, inclusions or exclusions, sustainability or unsustainable practices, stability or change, peace or conflict, order or disorder or any other 'big issue' - will be better addressed with an evidence based and nuanced understanding of personal relationships, particularly, intimate relationships and their construction through practices of intimacy.

\section{Acknowledgements}

Thank you to the editors for organising this special issue and their patience combined with constructive suggestions. I am grateful to the two anonymous referees who took rather different views but were both enormously helpful. Thanks also to Liz Stanley for her rapid response perceptive comments.

\section{References}

ANDERSON, B. (1991) Imagined Communities: Reflections on the Origin and Spread of Nationalism. London: Verso.

APPADURAI, A (1996) Modernity at Large: Cultural Dimensions of Globalization. Minneapolis: University of Minnesota Press.

BACKETT, K. (1982) Mothers and Fathers. London Macmillan.

BANAJI, S. (2006) Reading 'Bollywood' The Young Audience and Hindi Films. Basingstoke: Palgrave Macmillan.

BAUMAN, Z (1995) Life in fragments : essays in postmodern morality. Oxford: Blackwell.

BAUMAN, Z (2003) Liquid Love: On the Frailty of Human Bonds. Cambridge: Polity.

BECK, U and Beck-Gernsheim, E (1995) The Normal Chaos of Love. Cambridge: Polity.

BELL, S and Coleman, S (1999) The Anthropology of Friendship: Enduring Themes and Future Possibilities. In Bell, S and Coleman, S (eds.) The Anthropology of Friendship. Oxford: Berg.

BERNSTEIN, E. (2007) Temporarily Yours: Intimacy, Authenticity and the Commerce of Sex. Chicago: University of Chicago Press.

BERSCHEID, E., Schneider, M. and Omoto, A.M. (2008) Measuring Closeness: The Relationship Closeness Inventory (RCl) Revisited. In Mashek, D. and Aron, A. (Eds.) Handbook of Closeness and Intimacy. London: Taylor and Francis.

BJORNBERG, U. and Kollind, A.-K. (2005) Individualism and Families. Abingdon: Routledge.

BOURDIEU, P. (1998) Practical Reason: On the Theory of Action. Cambridge: Polity.

BRANNEN, J. and Nilsen, A. (2005) 'Individualisation, choice and structure: A discussion of current trends in sociological analysis', Sociological Review 53: 412-428. [doi:://dx.doi.org/10.1111/j.1467954X.2005.00559.x]

BURGESS, E. W. \& Locke, H. J. (1945) The Family: From Institution to Companionship. New York: American Book Company.

CALHOUN, C. (1991) Imagined Communities and Indirect Relationships: Large Scale Social Integration and the Transformation of Everyday Life. In P. Bourdieu \& J. S. Coleman (Eds.), Social Theory for a 
Changing Society., Boulder, CÓ: Ẃestview Press.

CALHOUN, C. (1992) The infrastructure of modernity: indirect social relationships, information technology and social integration. In H. Haferkamp \& N. J. Smelser (Eds.), Social Change and Modernity. Berkeley: University of California Press.

CALHOUN, C. (2008). 'Cosmopolitanism in the modern social imaginary', Dædalus, 137, 105-114. [doi:://dx.doi.org/10.1162/daed.2008.137.3.105]

CARRIER, J. (1999) People who can be friends: selves and social relationships. In Bell, S. and Coleman, S. (Eds.) The Anthropology of Friendship. Oxford: Berg.

CASTELLS, M. (1997) The Power of Identity. Oxford: Blackwell.

CARSTEN, J. (2000) Cultures of Relatedness: new approaches to the study of kinship. Cambridge: Cambridge University Press.

CARSTEN, J. (2004) After Kinship. Cambridge: Cambridge University Press.

CHARLES, N., Davies, C.A. and Harris, C. (2008) Families in Transition: Social Change, Family Formation and Kin Relationships. Bristol: Policy Press.

CHARSLEY, K. (2005) 'Unhappy husbands: Masculinity and migration in transnational Pakistani marriages', Journal of the Royal Anthropological Institute, 11, 85-105. [doi:://dx.doi.org/10.1111/j.14679655.2005.00227.x]

CLAYDEN, J. \& Stein, J. (2005) Mentoring young people leaving care: someone for me. York: Joseph Rowntree Foundation.

COLE, J. \& Thomas, L. M. (2009) Love in Africa. Chicago: University of Chicago Press.

CONNELL, R. (2007) Southern Theory: The global dynamics of knowledge in social science. Sydney: Allen \& Unwin.

CROLL, E. J. (2006) 'The Intergenerational Contract in the Changing Asian Family', Oxford Development Studies, 34, 473-491. [doi:://dx.doi.org/10.1080/13600810601045833]

CROSSLEY, N. (2007) Reflexive Embodiment in Contemporary Society: The Body in Late Modern Society.London: McGraw Hill.

CROW, G. (2002) Social Solidarities. Buckingham: Open University Press.

DING, Y. and Ho, S.-Y. (2008) Beyond Sex Work: An Analysis of Xiajies' Understanding of Work in the Pearl River Delta Area, China. In Jackson, S., Liu, J. and Woo, J. (Eds.) EastAsian Sexualities. London: Zed Books.

DU, S. (2008) "With One Word and One Strength" Intimacy among the Lahu of Southwest China. In W. R. Jankowiak (Ed.), Intimacies: Love + Sex Across Cultures. (pp. 95-121), New York: Columbia University Press.

DUNCAN, S. \& Smith, D. (2006) 'Individualisation versus the geography of 'new' families', Twenty-First Century Society, 1, 167 - 189. [doi:://dx.doi.org/10.1080/17450140600906955]

DUNCOMBE, J. and Marsden, D. (1995) Can Men Love? 'Reading', 'Staging' and 'Resisting' the Romance. In Pearce, L. and Stacey, J. (Eds.) Romance Revisited: Lawrence \& Wishart.

EVANS, M. (2003) Love An Unromantic Discussion. Cambridge: Polity.

FONG, V. L. (2004). Only Hope: Coming of Age Under China's One Child Policy, Stanford: Stanford University Press.

FOUCAULT, M. (1978) The History of Sexuality Vol 1. London: Penguin.

GABB J. (2008) Researching Intimacy in Families. Basingstoke: Palgrave Macmillan [doi:://dx.doi.org/10.1057/9780230227668]

GAGNON, J. and Simon, W. (1973) Sexual Conduct: The social sources of human sexuality. Chicago: Aldine.

GIDDENS, A. (1984) The Constitution of Society: Outline of the theory of structuration. Cambridge: Polity Press.

GIDDENS, A. (1991). Modernity and Self-Identity: Self and Society in the Late Modern Age. Cambridge: Polity Press.

GIDDENS, A. (1992) The Transformation of Intimacy. Cambridge: Polity Press. 
GILLIES, V. (2005) 'Raising the "Meritocracy" Parenting and the Individualization of Social Class', Sociology 39: 835-853. [doi:://dx.doi.org/10.1177/0038038505058368]

GILLIES, V. (2007) Marginalised Mothers: Exploring Working-Class Experiences of Parenting. London: Routledge.

HARRIS, S. R. (2006) The Everyday Meaning of Marital Equality. In J. Gubrium, Holstein, J. (Ed.).

HANSEN, M. H. \& Pang, C. (2010) Idealizing Individual Choice: Work, Love and Family in the Eyes of Young Rural Chinese. In Hansen M H \& Svarverud R (Eds.), iChina: The Rise of the Individual in Modern Chinese Society. Copenhagen: NIAS.

HERTZ, R. (1986) More Equal than others: women and men in dual career marriages. Berkeley: University of California Press.

HEWITT, J. P. (2007) Self and Society: A Symbolic Interactionist Social Psychology Boston: Allyn and Bacon.

HIRSCH, J.S. (2007) "Love Makes a Family" Globalization, Companionate Marriage, and the Modenization of Gender Inequality. In Padilla M B, Hirsch J S, Munoz-Laboy M, Sember R E \& Parker R G (Eds.) Love and Globalization:Transformations of Intimacy in the Contemporary World. Nashville: Vanderbelt University Press.

HIRSCH, J.S. and Wardlow, H. (2006) Modern Loves: The Anthropology of Romantic Courtship and Companionate Marriage.Michigan: The University of Michigan Press.

HOCHSCHILD, A. (2003) Love and Gold. In Ehrenreich B \& Hochschild A (Eds.), Global Woman. London: Granta Books.

HOCHSCHILD, A. (2003b) The Commercialization of Intimate Life Berkeley: University of California Press.

HOLDSWORTH, C. \& Morgan, D. (2007) 'Revisiting the Generalized Other: An Exploration', Sociology, 41, 401-417. [doi:://dx.doi.org/10.1177/0038038507076614]

HUANG, S. \& Yeoh, B. S. A. (2005) Transnational families and their children's education: China's 'study mothers' in Singapore. Global Networks, 5, 379-400. [doi:://dx.doi.org/10.1111/j.1471-0374.2005.00125.x]

IKELS, C. (2004) Filial piety, practice and discourse in contemporary East Asia. Stanford: Stanford University Press.

ILLOUZ, E. (2007) Cold Intimacies: the making of emotional capitalism, Cambridge: Polity.

IRWIN, S. (2005) Reshaping Social Life London: Routledge.

JAMIESON, L. (1998) Intimacy: Personal relationships in modern societies Polity Press, Cambridge.

JAMIESON, L. (1999) 'Intimacy Transformed? A Critical Look At The 'Pure Relationship', Sociology 33:477494 [doi:://dx.doi.org/10.1017/S0038038599000310]

JAMIESON, L., Morgan, D., Crow, G., Allan, G. (2006) 'Friends, Neighbours and Distant Partners:

Extending or Decentring Family Relationships?' Sociological Research Online 11.

JANELLI, R. L. \& Yim, D. (2004) The transformation of filial piety in contemporary South Korea. In C. Ikels (Ed.), Filial piety, practice and discourse in contemporary East Asia. Stanford: Stanford University Press.

JANKOWIAK, W.R. (Ed.) (2008) Intimacies: Love + Sex Across Cultures. New York: Columbia University Press.

JANKOWIAK, W.R. and Paladino, T. (2008) Desiring Sex, Longing for Love: A Tripartite Conumdrum. In Jankowiak, W.R. (Ed.) Intimacies: Love + Sex Across Cultures. New York: Columbia University Press.

KURZ, D. (2006) Keeping tabs on teenagers. In Gubrium and Holstein (Eds) Couples, Kids and Family Life, Oxford: Oxford University Press.

LAREAU, A. (2003) Unequal Childhoods: Class, Race and Family Life. Berkeley: University of California Press.

LEVITT, P. \& Schiller, N. G. (2004) Conceptualizing Simultaneity: A Transnational Social Field Perspective on Society. International Migration Review, 38, 1002-1039. [doi:://dx.doi.org/10.1111/j.1747-

7379.2004.tb00227.x]

LI, Yinhe (2008) 'Chinese Women's Stories of Love, Marriage and Sexuality' in Jackson, S., Liu, J. and Woo, J. (eds.) EastAsian Sexualities: Modernity, Gender and New Sexual Cultures. London, NY: Zed Books.

MACFARLANE (1978) The Origins of English Individualism: Some Surprises'. Theory and Society 6: 255277. 
MACPHERSON, C. (1962) The Political Theory of Possessive Individualism: Hobbes to Locke. Oxford: Oxford University Press.

MAGAZINE, R. and Sanchez, M.A.R. (2007) Continuity and Change in San Pedro Tlalcuapan, Mexico: Childhood, Social Reproduction and Transnational Migration In Cole, J. and Durham, D. (Eds.) Generation and Globalization: Youth, Age and Family in the New World Economy. Bloomington: Indiana University Press.

MCNAY, L. (2008) Against Recognition. Cambridge: Polity Press.

MEAD, G. H. (1934). Mind, Self and Society. Chicago: University Chicago Press.

MILLER, D. (2007) What is a Relationship? Is Kinship Negotiated Experience? Ethnos, 72, 535-554. [doi:://dx.doi.org/10.1080/00141840701768334]

MODY, P. (2008) The Intimate State: Love-Marriage and the Law in Delhi. New Delhi: Routledge.

MOHANTY, C.T. (2003) Feminism without Borders: Decolonizing Theory, Practicising Solidarity. Durham, NC: Duke University Press.

MORGAN, D. (1996) Family Connections: An Introduction to Family Studies. Cambridge: Polity Press.

MORGAN, D. (2009) Acquaintances: The Space Between Intimates and Strangers: Open University Press.

MORGAN, D. (2011) Rethinking Family Practices. Basingstoke: Palgrave Macmillan.

[doi:://dx.doi.org/10.1057/9780230304680]

MORLEY, D. (1986) Family Television: Cultural Power and Domestic Leisure, London: Comedia.

OINONEN, E. (2008) Families in Converging Europe: a comparison of forms, structures and ideals Basingstoke: Palgrave Macmillan.

PADILLA, M. B., Hirsch, J. S., Munoz-Laboy, M., Sember, R. E. \& Parker, R. G. (2007) Love and Globalization: Transformations of Intimacy in the Contemporary World. Nashville: Vanderbilt University Press.

PARSONS, T. \& Bales, R. (1956). Family, socialisation and interaction process, London: Routledge and Kegan Paul.

PATEMAN, C. (1988) The Sexual Contract. Polity Press, Cambridge.

PHILIP, K. (2008). 'She's My Second Mum: Young People Building Relationships in Uncertain Circumstances', Child Care in Practice, 14, 19-33. [doi:://dx.doi.org/10.1080/13575270701733674]

QUAH, S.R. (2008) Families in Asia: Home and Kin. London: Routledge.

REBHUN, L.A. (1999) The Heart Is Unknown Country: Love in the Changing Economy of Northeast Brazil. Stanford: Stanford University Press.

ROSE, N. (1996) Inventing Our Selves: Psychology, Power and Personhood. Cambridge: University Press. [doi:://dx.doi.org/10.1017/CBO9780511752179]

ROSENEIL S. and Budgeon S. (2004) 'Cultures of Intimacy and Care Beyond the Family: Personal Life and Social Change in the Early Twenty-First Century', Current Sociology, 52(2).

[doi:://dx.doi.org/10.1177/0011392104041798]

ROSENFELD, M. J. (2007). The Age of Independence: Interracial Unions, Same Sex Unions, and the Changing American Family . Cambridge, Massachusetts: Harvard University Press.

RÖTTGER-RÖSSLER, B. (2008) Voiced Intimacies: Verbalized Experiences of Love and Sexuality in an Indonesian Society. In Jankowiak, W.R. (Ed.) Intimacies: Love + Sex Across Cultures. New York: Columbia University Press.

SANDERS, T. (2008) 'Male Sexual Scripts: Intimacy, Sexuality and Pleasure in the Purchase of Commercial Sex'. Sociology 42: 400-417. [doi:://dx.doi.org/10.1177/0038038508088833]

SCHUTZ, A. (1932) Der sinnhafte Aufbau der sozialen Welt. English translation: Phenomenology of the Social World. Trans. George Walsh and Frederick Lehnert. Evanston, IL: Northwestern University Press, 1967

SHAW, A. (2000) Kinship and Continuity: Pakistani Families in Britain. London: Routledge.

SHAW, A. \& Charsley, K. (2006). 'Rishtas: adding emotion to strategy in understanding British Pakistani transnational marriages', Global Networks, 6, 405-421. [doi:://dx.doi.org/10.1111/j.1471-0374.2006.00152.x]

SHEN, H.-H. (2008) Becoming 'the First Wives': Gender, Intimacy and the Regional Economy across the 
Taiwan Strait. In Jackson, S., Liu, J. and Woo, J. (eds.) EastAsian Sexualities: Modernity, Gender and New Sexual Cultures. London, NY: Zed Books.

SILVA, E. (2010) Technology, Culture, Family: Influences on Home Life. Basingstoke: Palgrave Macmillan. [doi:://dx.doi.org/10.1057/9780230297029]

SILVER, A. (1997) Two different sorts of commerce: Friendship and strangership in civil society. In J. Weintraub \& K. Kumar (Eds.), Public and Private in Thought and Practice. Chicago: Universtiy of Chicago Press.

SMART, C. and Shipman, B. (2004) 'Visions in Monochrome: Families, Marriage and the Individualization Thesis '. British Journal of Sociology 55: 491-509.

SMART, C. (2007) Personal Life: New Directions In Sociological Thinking, Cambridge: Polity.

SMITH, D. (1987) The Everyday World As Problematic: A feminist sociology. Milton Keynes: Open University Press.

SOLOMAN, Y., Warin J., Lewis C. and Langford W. (2002) 'Intimate talk between parents and their teenage children: Democratic openness or covert control?', Sociology, 36 (4): 965-983

[doi:://dx.doi.org/10.1177/003803850203600409]

SPENCER, L. and Pahl, R (2006) Rethinking Friendship: Hidden Solidarities Today. Princeton University Press.

STANLEY, L., Dampier, H. \& Salter, A. (2010) 'Olive Schreiner globalising social inquiry: A feminist analytics of globalisation', The Sociological Review, 58, 657-680. [doi:://dx.doi.org/10.1111/j.1467954X.2010.01945.X]

THORNTON, A. (2001) The Developmental Paradigm, Reading History Sideways, and Family Change. Demography, 38, 449-465. [doi:://dx.doi.org/10.1353/dem.2001.0039]

THORNTON, A. (2005) Reading History Sideways: The Fallacy and Enduring Impact of the Developmental Paradigm on Family Life, Chicago: Chicago University Press.

UBEROI, P. (2006) Freedom and Destiny: Gender, Family and Popular Culture in India. New Delhi Oxford University Press.

URRY, J. (2000) Sociology Beyond Societies, London: Routledge.

WALKERDINE, V. and Lucey, H. (1989) Democracy in the Kitchen: Regulating Mothers and Socialising Daughters. London: Virago.

WICKHAM, G., Kendall, G. (2007)'Critical Discourse Analysis, Description, Explanation, Causes: Foucault's Inspiration Versus Weber's Perspiration', Forum Qualitative Sozialforschung / Forum: Qualitative Social Research: <http://www.qualitative-research.net/index.php/fqs/article/view/252/555>.

WELLMAN, B., Hogan, B., Berg, K., Boase, J., Carrasco, J.-A., Côté, R., Kayahara, J., Kennedy, T.L.M. and Tran, P. (2006) 'Connected Lives: The Project' in Purcell, P. (ed.) Networked Neighbourhoods. London: Springer.

WEEKS, J., Heapy, B. and Donovan, C. (2001) Same Sex Intimacies. London: Routledge.

WEEKS, J. (2007) The World We Have Won: The Remaking of Erotic and Intimate Life. London: Routledge.

WIMMER, A. and Schiller N. G. (2002) 'Methodological nationalism and beyond: nation-state building, migration and the social sciences', Global Networks, 2, 301-334.

YAN, Y. (2010) Introduction: Conflicting Images of the Individual and Contested Process of Individualization. In M. H. Hansen \& R. Svarverud (Eds.), iChina: the Rise of the Individual in Modern Chinese Society. Copenhagen: NIAS. 